\title{
NuEVA INTERPRETACIÓN SOBRE LA SIMBOLOGÍA DE LA BANDEJA PROTOHISTÓRICA de El Gandul (Alcalá de Guadaira, Sevilla)
}

New Proposal on the Symbology of the Protohistoric Tray of El Gandul (Alcalá de Guadaira, Seville)

\section{ÁLVARO GÓMEZ PEÑA [D}

Dpto. de Prehistoria y Arqueología. Universidad de Sevilla. agomez19@us.es

\section{RESUMEN:}

En el presente artículo se realiza una nueva propuesta acerca del universo simbólico reflejado en la bandeja de bronce de El Gandul (Alcalá de Guadaíra, Sevilla). En primer lugar se presenta la pieza prestando atención a sus características formales y cronológicas. En un segundo apartado se realiza un resumen historiográfico de las anteriores hipótesis publicadas sobre parte o la totalidad de la simbología de la fuente. Tras dicho repaso se procede a describir la nueva propuesta, basada en el reflejo del mitema que tiene por objeto el empleo de una planta con propiedades en ocasiones rejuvenecedoras, en otras inmortales, como medio para alcanzar una vida eterna y/o revigorizada. Dicho mitema aparece reflejado tanto en la Epopeya de Gilgamesh como en diversos mitos helenos. Desde esta perspectiva se analizan en último lugar los diferentes elementos representados en la bandeja de El Gandul, desde la serpiente que repta bajo los peces a la forma taurodérmica que presenta el perfil de la pieza.

Palabras clave: planta de la inmortalidad, resurrección, escatología fenicia, piel de toro, Toro Celeste.

\section{Abstract:}

This paper deals with the symbolic universe reflected in the bronze plate of El Gandul (Alcala de Guadaira, Seville). First, the piece is presented paying attention to its formal characteristics and its chronology. In a second section, a historiographic summary of the previous published hypotheses about its symbolism is realised. After this review, we proceed to describe the new proposal, based on the mytheme of a plant with youthfulness or immortalizing properties, as a means to achieve an eternal and/or reinvigorated life. Such mytheme is reflected both in the Epic of Gilgamesh and in various Greek myths. From this perspective, we discussed different elements represented in the plate of El Gandul, from the snake which crawls under the fishes to the bull's hide shape of the piece.

Key words: plant of immortality, resurrection, Phoenician eschatology, bull's hide, Bull of Heaven. 
El friso concluye en ambas esquinas en sendas palmetas individuales, cuyo vigor parece surgir, respectivamente, de la lengua que asoma incisiva

de la serpiente y la toca en su base y, en el otro extremo, de la misma cola: es la serpiente moradora de la profundidad, la que vigoriza y rejuvenece a las plantas, la que al mismo tiempo parece atraída por su fragancia, como la serpiente que se apodera de la planta inmortal, escondida en un estanque secreto, que será buscada por el héroe, como narra la épica de Gilgames

(Olmos 2007-2008: 111-112)

\section{INTRODUCCIÓN ${ }^{1}$}

Hasta el momento se conocen procedentes del mundo funerario tartésico dos fuentes ${ }^{2}$ de bronce con asas apuntadas (fig. 1). La primera de ellas fue hallada en la tumba 16 de la necrópolis onubense de La Joya (Huelva). Se trata de una bandeja de bronce con centro ovalado y fondo cóncavo. En cada extremo del mismo se colocó una agarradera sujetada con nueve remaches. Cada una de ellas fue decorada con motivos florales simétricos, tomando el protagonismo una palmeta en su zona central (fig. 2). Dada su forma, desde su primera publicación se sopesó como paralelo la forma del lingote chipriota (Garrido y Orta 1978: 49).

La segunda de las bandejas procede de El Gandul. Fue dada a conocer a finales de los años ochenta por F. Fernández Gómez al tener conocimiento de su existencia en una colección particular del municipio sevillano de Alcalá de Guadaíra. Tras entrar en contacto con su propietario, éste no tuvo inconveniente en permitir el acceso

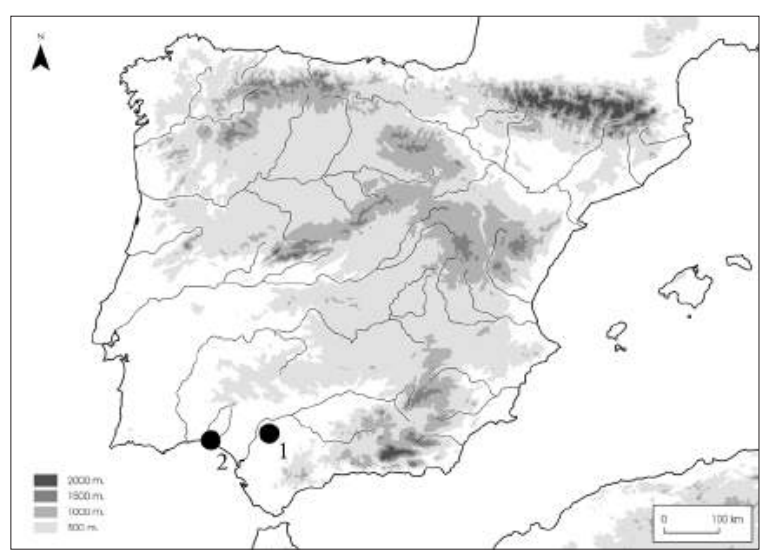

Fig. 1: Mapa con la localización de los yacimientos de los que proceden ambos ejemplares: 1) El Gandul (Alcalá de Guadaíra, Sevi1la). 2) La Joya (Huelva) (elaboración propia). a la misma para su estudio y posterior venta al Museo Arqueológico de Sevilla (Fernández Gómez 1989: 199). La pieza (fig. 3) se trata de un recipiente oval facturado en bronce de 42,6 cm de longitud entre sus puntos más distales. Igualmente presenta fragmentos de dos asas, con sus correspondientes remaches, que pudieron tener la misma forma que la del ejemplar onubense. Se estima que la longitud total del ejemplar alcalareño podría haber alcanzado aproximadamente los $54,2 \mathrm{~cm}$ de longitud (Fernández Gómez 1989: 200).

En cuanto a su decoración, la pieza alcalareña presenta una almendra central rodeada de palmetas y dos flores en cada uno de sus extremos. Ambas sirven de cierre compositivo a un posible estanque o laguna. En su interior se han representado cuatro peces que miran en dirección opuesta a la serpiente, la cual con la lengua bífida fuera recorre zigzagueante el fondo acuático. En un segundo nivel, en torno a dicha masa de agua se ha representado en un lateral una flor, similar a las que han sido grabadas en la almendra central, flanqueada por una esfinge y un león con alas. En sentido contrario, una fila compuesta por cada uno de estos seres se dirige hacia un vaso à chardon alado del que parece asomar un símbolo astral. Todo el conjunto se encuentra rematado en el borde por una greca dentellada y un motivo exterior a modo de cuerda. En cuanto a las asas, en pésimo estado de conservación, parecen tener grabadas una gran palmeta de cuenco, reconstruida por Fernández Gómez a partir del paralelo de La Joya (Fernández Gómez, 1989: 207).

La datación del ejemplar de El Gandul descansa en dos aspectos diferentes. Por una parte, en la cronología barajada para la tumba 16 de La Joya, fechada en el s. VII a.C. a partir de los platos de barniz rojo hallados en su interior (Torres 1999: 63). Por otro lado, en los paralelos iconográficos presentes en la eboraria tartésica y en las copas de bronce mediterráneas, los cuales permiten proponer la misma cronología (Jiménez Ávila 2003: 236). Ambas posibilidades cuadran sin problemas con el momento álgido de este tipo de repertorios figurativos orientales en todo el Mediterráneo (Jiménez Ávila 2002: 140). Del mismo modo, el análisis realizado por S. Rovira poco después de su hallazgo muestra claras semejanzas en cuanto a los aspectos tecnológicos y tipológicos de la bandeja con otras piezas del período orientalizante (Rovira 1989).

En vista de estos datos, ambos bronces se complementan desde el punto de vista arqueológico. Mientras el ejemplar encontrado en Huelva aporta datos interesantes 
para valorar su contexto, el ejemplar alcalareño ofrece información de suma importancia para comprender su simbología. En este análisis se tratará de dar explicación a la mitología grabada en este último para seguir avanzando en la comprensión sobre la función que ambas piezas pudieron tener dentro de la escatología funeraria tartésica.

\section{REPASO HISTORIOGRÁFICO SOBRE SU SIM- BOLOGÍA}

Resulta sorprendente no encontrar una publicación que de manera monográfica se haya centrado en la posible simbología de esta pieza desde que la publicara Fernández Gómez (1989; 1991). El único análisis que ha tratado esta fuente con cierto detenimiento es el de R. Olmos a propósito del posible cosmos mítico representado en ella, si bien dentro de un estudio más general junto a otros objetos y temas mitológicos ajenos al ejemplar alcalareño (Olmos 2003; 2007-2008). Sí existen en cambio referencias puntuales sobre el significado de algunos elementos de la bandeja de El Gandul, de enorme interés para el presente estudio (Jiménez Ávila 2002: 139-146; 2003: 235-236; Uroz 2006: 144-145; Olmos 2007-2008; García Cardiel 2009: 60; San Martín 2014: 218).

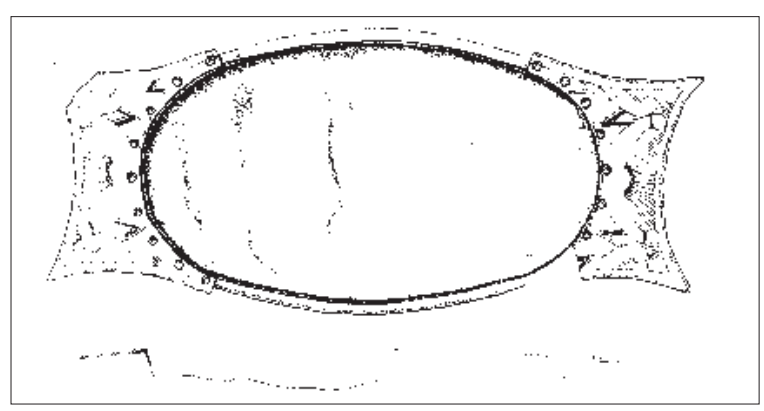

Fig. 2: Bandeja de La Joya (Jiménez Ávila 2002: 451, Lam. XXIII.47).

En la primera publicación en la que se daba a conocer esta fuente, Fernández Gómez vinculó su simbología con posibles ritos de purificación funerarios o de otro tipo, haciendo alusión los motivos en ella grabados a tales rituales. Siguiendo a este autor, todo el conjunto estaría representando una cosmografía donde la parte central haría referencia a las profundidades marinas y terrestres, mientras que por encima de dicha escena se circunscribiría una línea de tierra que estaría contraponiendo la vida, figurada por la palmeta, a la muerte, a través del vaso à chardon (Fernández Gómez 1989: 216-217). Esta misma idea ha sido seguida en líneas generales por otros autores (Jiménez Flores 2002: 200; Jiménez Ávila 2003: 236; San Martín 2014: 218).

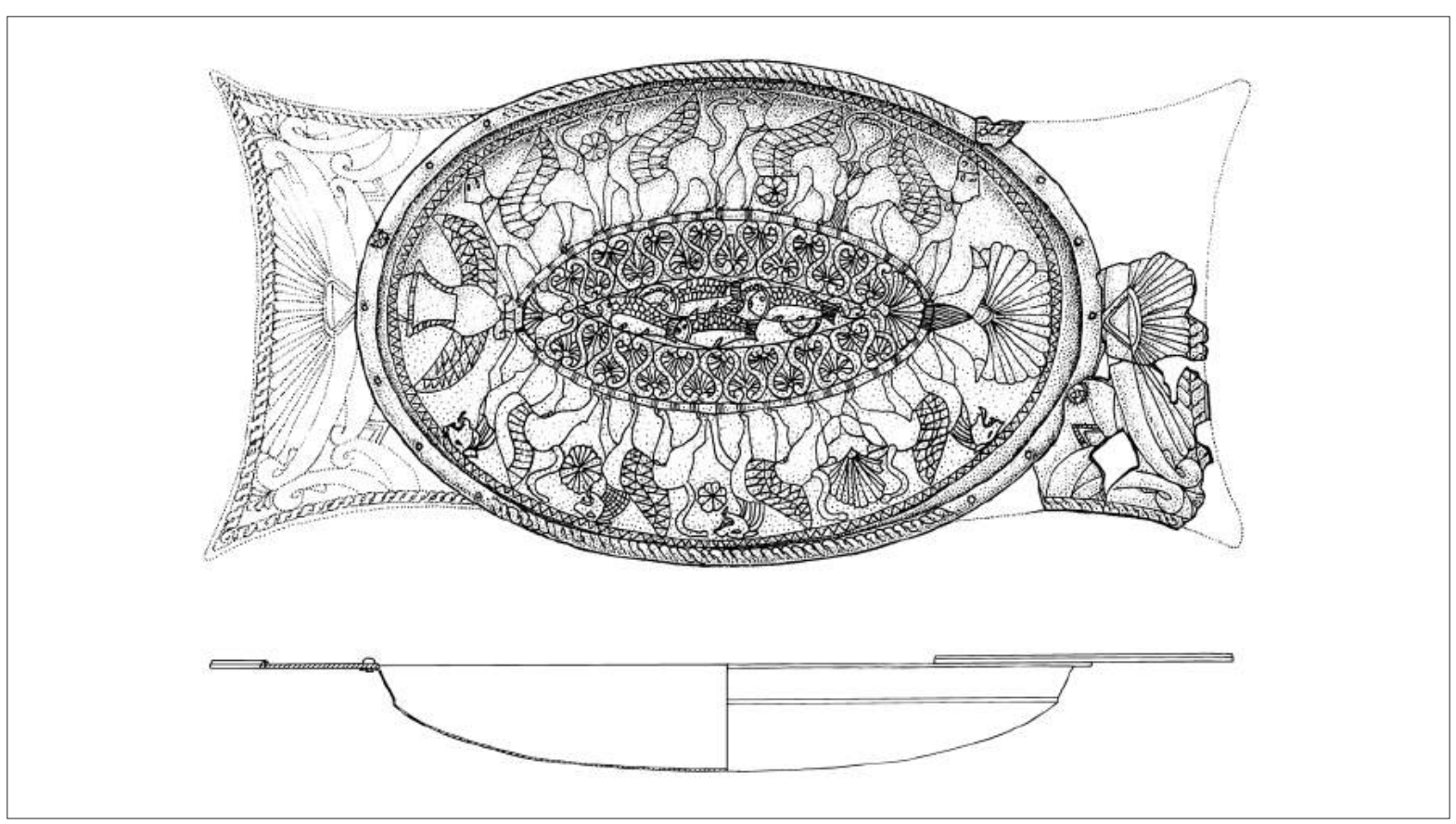

Fig. 3: Fuente de El Gandul (Jiménez Ávila 2002: 451, Lam. XXIII.48). 
Por otro lado, J. Jiménez Ávila complementó en su monografía sobre la toréutica orientalizante el análisis simbólico con aspectos funcionales sobre las fuentes de El Gandul y La Joya, indicando que este último asunto es difícil de averiguar a partir de sus detalles iconográficos (Jiménez Ávila 2002: 42). En dicha publicación, este autor realizó conexiones entre ambas piezas y las besugueras actuales a partir de aspectos formales, decorativos y contextuales. Entre los primeros destacó la forma oval de las bandejas y el perfil 'aletiforme' de sus asideros. Con respecto a los detalles decorativos llamó la atención sobre los peces que nadan en el fondo del ejemplar alcalareño. Los datos contextuales proceden del hallazgo de espinas de pescado en algunas tumbas de la necrópolis tartésica de La Joya, si bien él mismo indicó que no se han hallado restos de pescado asociados al ejemplar onubense (Jiménez Ávila 2002: 142).

Por otra parte se encuentra la primera interpretación propuesta por Olmos. En una primera aproximación, este autor planteó que la bandeja estaría reflejando un mitema común a diversas culturas a través del cual se narra el regreso del sol hacia oriente en un recipiente usado como barca tras su viaje diario por el firmamento (Olmos 2003: 45). Complementando dicha idea solar, la flor de loto aparecería expandiendo los rayos de sus pétalos mientras los leones y las esfinges aladas estarían actuando como seres protectores de las divinidades (Olmos 2003: 45).

Años más tarde este mismo autor vería en algunos pasajes del poema de Gilgamesh el mitema ideal para profundizar en la interpretación de parte de la simbología de esta bandeja (Olmos 2007-2008: 111). Con base en esta narración se estaría ante un microcosmos de bronce en el que la serpiente que se halla al fondo del estanque central y la flor que se encuentra en la orilla podrían tener relación con la serpiente y la flor de la vida de la épica de Gilgamesh.

Esta última propuesta ideada por Olmos resulta especialmente sugerente por los motivos que se expondrán a lo largo de las siguientes páginas. Sin embargo, más allá de dejar anotada esta idea en pocas líneas, los detalles iconográficos de esta bandeja permiten profundizar en su simbología de modo más preciso. Así, al análisis pormenorizado de cada elemento representado en la fuente, hay que sumar dos conceptos especialmente relevantes. Por una parte, el recurso iconográfico para hacer alusión a un rito arquetípico tímidamente tratado por otros autores (Almagro-Gorbea et al. 2011-2012). De otro lado, la forma de piel de toro que presenta el ejemplar (Escacena e Izquierdo 2000).

\section{ANÁLISIS SIMBÓLICO DE LA PIEZA}

\section{EL MITEMA DE LA FLOR REVIGORIZANTE}

El primer asunto a tratar sobre la simbología de la bandeja de El Gandul es el del mitema de la flor revigorizante. Éste se basa en el uso por parte de diferentes personajes míticos y heroicos de una flor con propiedades de resurrección y rejuvenecimiento. Para conseguir las características esenciales de esta planta, lo habitual es oler su aroma, ingerirla o frotarla contra la piel. Entre los ejemplos documentados se encuentra el episodio de Gilgamesh en busca de la planta de la juventud, diversos mitos griegos que tienen como denominador común a un personaje llamado Glauco y, en último término, el universo simbólico que se grabó en la fuente de El Gandul.

\section{EL POEMA DE GILGAMESH}

La epopeya de Gilgamesh es una de las más antiguas narraciones que ha llegado hasta nuestros días a través de varios fragmentos de diversas copias elaboradas con el paso de los siglos. En esta historia se cuenta parte de la vida del rey de la ciudad de Uruk. Al comienzo de la misma, Gilgamesh es mostrado como un personaje tiránico con sus súbditos. Dada su mala reputación, los ciudadanos deciden quejarse ante los dioses. Éstos, escuchando las súplicas del pueblo, deciden enviar a Enkidu, un personaje salvaje, con la intención de enfrentar a ambos. Sin embargo, al entablar combate cada uno descubre en el otro cualidades con las que se identifica, por lo que en vez de darse muerte acaban convirtiéndose en amigos inseparables.

La historia narra a partir de entonces las virtudes que se esperan encontrar en personajes de la realeza cuyo carácter pretende ser heroico. Así, ambos acometen episodios singulares como el asesinato de Humbaba en el Bosque de los Cedros y la lucha contra el Toro Celeste, hasta el fallecimiento de Enkidu. La muerte de su amigo deja afectado a Gilgamesh hasta el punto de entrar en una grave crisis existencial al ser consciente de que el mismo destino de Enkidu le tocará a él tarde o temprano. Este despertar de la conciencia sobre la finitud de la vida hace a Gilgamesh emprender un largo viaje para tratar de buscar la inmortalidad. Dicho camino le lleva en busca de Utnapishtim, el único humano que había conseguido ser inmortal tras sobrevivir al diluvio mesopotámico. Éste y su esposa le confiesan varias alternativas a modo de pruebas iniciáticas para tratar de alcanzar la vida eterna. 
Sin embargo, Gilgamesh fracasa en todas. Ante los sucesivos fracasos de Gilgamesh por alcanzar la inmortalidad, la esposa de Utnapishtim le reclama a su marido que le dé una última solución que le consuele. Es así como surge la posibilidad de rejuvenecer y alargar su vigorosidad:

Gilgamesh, tú viniste hasta aquí con gran dolor y fatiga: / ¿Qué te doy a dar, (cuando) regresas a tu país? / Voy a revelar<te> un misterio, / A [comu]nicar[te] un [secr]eto de los dioses: / (Se trata de) una planta con la raíz semejante a (la del) Falso-Jazmín / Y cuyas espinas son como (las de) la Zarza (listas para) pin[char]te [las manos?]. / Si consigues hacerte con ella, [Habrás encontrado la Vida (Prolongada)]» / Al oír esto, Gilgamesh excavó un [hoyo (i)] / Para desenterrar gruesas piedras, / Las cuales le arrastraron hasta el [fondo del mar], [(Donde) encontró la planta]. / Se apoderó de ella (pese a) los pin[chazos]. / Luego, tras liberar sus pies de las pesadas piedras, / El mar lo depositó en la orilla. I Y Gilgamesh le habló a él, a UrShanabi el Barquero, / «UrShanabi, ésta es la planta contra el miedo (a la muerte): / Con ella, se puede recobrar la vitalidad. / Voy a llevarla a Uruk, la de los cercados, donde, para probar (su eficacia) haré que la tome [un viejo]: / Porque su nombre es «El viejo rejuvenece». / (Luego) la tomaré yo mismo, para recuperar mi juventud». / Tras doscientos kilómetros, comieron algo; / (Después) de trescientos (más), acamparon. / Al ver Gilgamesh un pozo de agua fresca, / Entró en él para bañarse / Pero al olor de la planta, una serpiente / Salió [furti] vamente de su madriguera y se la llevó: / De regreso se quitó una piel. / Gilgamesh, [en]tonces, se sentó y lloró, / Y las lágrimas resbalaban por sus mejillas.

(Bottéro 2015 [1998]: 198-200).

Como se ve en el texto, la prueba consiste en hallar una planta espinosa que crece en las Aguas del Abismo. Sin embargo, en un descuido Gilgamesh pierde toda oportunidad. Mientras se baña en un pozo de agua fresca, una serpiente huele la fragancia de la flor y consigue mudar de piel, lo que se ha interpretado como un claro símbolo de regeneración y, por extensión en otros contextos, de resurrección (Eliade 1999 [1976]: 117). Dentro del mismo mitema pueden englobarse otros episodios mitológicos en los que la flor es el elemento que guarda la esencia de la inmortalidad/rejuvenecimiento.

\section{EL MITEMA EN EL MUNDO GRIEGO}

De la tradición helena proceden diversos mitos que presentan un esquema similar al de la epopeya de Gilgamesh ${ }^{3}$. El primero guarda relación con el mito de Glauco, pescador de Antedón, en Beocia, quien consigue la inmortalidad después de ingerir una planta maravillosa, convirtiéndose en divinidad marina con carácter oracular para aconsejar a los navegantes (Rodríguez Somolinos 2006: 11-12).

Otra narración tiene por protagonista a otro Glauco, esta vez de Potnias, hijo de Sísifo y rey de Corinto que se convirtió en dios marino. Tras haber hallado por casualidad la fuente de la inmortalidad se lanzó a por ella, con tan mala fortuna que no pudo después demostrarle a nadie que había adquirido tal condición, por lo que fue lanzado al mar y desde entonces sólo predecía desgracias recorriendo las orillas.

El tercero tiene como actor principal de nuevo a otro Glauco, hijo del rey Minos de Creta. La narración fue recogida por Sófocles, Eurípides y Esquilo. En ella se cuenta que Glauco murió de niño al caer en una tinaja con miel. Minos, desconsolado, decide realizar una consulta oracular y los Curetes le indican que a su hijo puede resucitarle el hombre que resuelva un enigma en concreto. Quien consigue desvelarlo es el adivino Polidio, siendo encerrado con el cadáver de Glauco. En este punto de la narración, a Polidio se le aparece una serpiente y decide matarla para proteger el cadáver. A ella le sigue otro áspid que observa que la que le antecedió ha muerto, por lo que opta por llevarle una flor que la hace resucitar. Con ella, Polidio frota el cuerpo del muchacho y consigue devolverle a la vida (Rodríguez Somolinos 2006: 13).

Por último existe otro episodio que ahonda en el carácter del mitema aquí señalado. Se trata de la historia contada por Claudio Eliano, quien vivió entre el s. II y el III d.C., a propósito de la recompensa que otorgó Zeus a los delatores del robo del fuego por parte de Prometeo:

El nombre de dipsás denuncia la peculiar actividad de este reptil. Es más pequeña que la víbora, pero mata más de prisa. Los mordidos por ella arden de sed, se inflaman en deseos de beber, beben sin tino y, al instante, revientan. Sóstrato dice que la dipsás es blanca, pero que tiene dos franjas negras en la cola. Tengo entendido que algunos las llaman también prestéres; otros, kausónes. La verdad es que abruman a esta criatura con un montón de nombres. La llaman también, según dice, melanourós, y otros, ammobátes. $Y$, si oyeres que la llaman también kentrís, piensa que se refieren a la misma que yo.

$Y$ es preciso que yo repita una historia (que conozco por haber oído contarla), referente a este reptil, para que no se me achaque desconocimiento de ella.

Es fama que Prometeo robó el fuego, y dice la historia que Zeus montó en cólera y que dio a los delatores del robo una droga preservadora de la vejez. He sido informado de que ellos la cogieron y la pusieron sobre un asno. Éste se puso a caminar con su carga en el lomo; era verano y el asno, que estaba sediento, 
llegó hasta una fuente, acuciado por la necesidad de beber. La serpiente, que estaba guardando la fuente, quiso estorbárselo y obligarle a retroceder, y el asno, asustado, dio a la serpiente, como recompensa por haberle perdonado la vida, la droga que casualmente llevaba. $Y$ así hubo un intercambio de dones: el asno pudo beber y la serpiente se despojó de la vejez, recibiendo por añadidura, según refiere la historia, la sed del asno.

¿Qué decís? ¿Que soy yo el inventor de la leyenda? Lo niego, porque antes que yo la versificaron Sófocles, el poeta trágico, Dinóloco, rival de Epicarmo, e Íbico de Regio, y además, los poetas cómicos Aristias y Apolófanes

(Claudio Eliano, De natura animalium VI, 51; trad. Díaz-Regañón 1984: 289-290).

En todos los casos el mitema es similar. Cuatro son los elementos que ha señalado Rodríguez Somolinos que se repiten: (1) el salto al mar o a la miel, (2) los oráculos, (3) la flor como medio hacia la inmortalidad/resurrección y (4) el nombre del protagonista (Rodríguez Somolinos 2006: 14). Este último hecho, la repetición del nombre del actor, podría indicar la existencia de una figura mítica, un personaje primigenio, que habría ido con el paso del tiempo diferenciándose en identidades diversas pero manteniendo siempre la esencia del proceso iniciático que sufre (Rodríguez Somolinos 2006: 14).

\section{LA BANDEJA DE EL GANDUL}

En último término resta por detallar la simbología que presenta la fuente alcalareña.

Empezando por lo que podría interpretarse como laguna aparece un escenario similar al lugar en que Gilgamesh tomó su fatídico baño y acabó perdiendo la flor. En este caso, la charca queda testimoniada por los peces que tan sólo habrían sido representados para indicar al espectador que dicha almendra central estaría cubierta de agua. Igualmente las palmetas-liras alrededor de ese espacio servirían de límite del mismo. Entre ellas la serpiente trata subrepticiamente de alcanzar la flor que se encuentra en la orilla. Sin embargo, y a diferencia del pasaje de Gilgamesh, la planta se encuentra custodiada por dos seres protectores que impiden que el áspid consiga su propósito. En el caso de la bandeja de El Gandul, gracias a dicha protección el difunto no tenía que temer por su resurrección en el Más Allá y podía alcanzar una nueva juventud en el plano divino. El éxito de tal empresa se ve reflejado en el vaso $a$ chardon, contenedor de las cenizas del fallecido, del que asoma un posible astro que sería la representación del difunto en su viaje al firmamento. Junto a él, una procesión de esfinges y leones le protegen durante el ritual.
Según esta interpretación hay que diferir de la opinión de Fernández Gómez sobre el significado de la presencia de la serpiente y los peces en la almendra central de la fuente como representaciones del mundo de las profundidades, el terrestre en el caso de la primera y el acuático en el de los segundos (Fernández Gómez 1989: 213). Ya se ha anotado que los peces no son más que una forma de indicar que ese espacio se trata de un medio acuoso y además sirven para tapar a la serpiente dándole un mayor carácter subrepticio. En cuanto a ésta, su papel, siguiendo el paralelismo con el pasaje de Gilgamesh, no sólo simboliza el mal, la piedra en el camino para desbaratar las intenciones del héroe mesopotámico, sino que también refleja con su muda de piel el carácter ctónico y por extensión de resurrección ligado al mundo funerario (Eliade 1999 [1976]: 117), cuestión que cuenta con varios paralelos en la península Ibérica (Uroz 2006: 112-113). Quizás, desde una lectura fenicia, este animal podría ser identificado con Yam, divinidad semítica antagónica a Baal que representa el caos y que era representada a veces en el Mediterráneo oriental como una serpiente que moraba en las aguas.

En cuanto a la flor, es necesario indicar que existen escasísimos estudios acerca de la identificación, la función y la simbología de la flora documentada en época protohistórica en la península Ibérica (Mata et al. 2007). Con respecto a las plantas de los mitos aquí comentados, se han hecho intentos por tratar de averiguar qué planta sería por una parte la shibu issakhir amelu -'el anciano se rejuvenece'- del poema de Gilgamesh (Wagner, 2011a: 44-45). Por otra, con respecto a las narraciones que envuelven a los diversos Glaucos, en algunos casos la planta es denominada como balis o ballis, por el nombre frigio del rey, lo que podría traducirse como «hierba real». En otros casos es llamada Diòs ánthos - 'flor de Zeus'- (Rodríguez Somolinos 2006: 13-14).

Además de lo acabado de comentar sobre la vinculación regia de esta planta, otro dato a destacar es el carácter solar y primigenio que se le atribuye:

\footnotetext{
El primero es de Alejandro Etolo (Alex. Aet. 1), quien dice que Glauco se lanzó al mar tras probar la hierba... «...que para el Sol resplandeciente hace crecer en primavera la tierra en las islas de los bienaventurados». Además el texto dice que esta hierba la ofrece el Sol a sus caballos para que puedan completar cada día su recorrido sin dejarse vencer por el cansancio. El segundo fragmento es un verso de Escrión de Samos, lírico del IV a.C., en el que alguien se dirige a Glauco diciéndole: «y encontraste la hierba de los dioses, que plantó Crono» (Aeschrio, SHell., 5). Así pues es una hierba divina, procedente de los tiempos primigenios.
}

(Rodríguez Somolinos 2006: 15) 
Con todos estos datos, puede afirmarse que la flor representada en la bandeja de El Gandul se trata de una planta con propiedades ambrosíacas, habiendo propuesto algunos autores su identificación con una flor de loto (López Pardo 2006: 140). Tenga o no un referente real, lo importante para el caso aquí analizado es que la planta simboliza el carácter regenerador que quiere alcanzar el héroe. Estoy de acuerdo con C. G. Wagner en que en ningún caso simbolizaría al árbol de la vida, interpretación que le dio Fernández Gómez a la palmeta (Fernández Gómez 1989: 210), dados los paralelos textuales antes indicados.

Por su parte, las esfinges y los leones tienen un simbolismo similar en el imaginario protohistórico. Las primeras, con cuerpo leonino y cabeza humana, son el animal híbrido más abundantemente representado en los bronces tartésicos de la península Ibérica. Su origen se encuentra en el Antiguo Egipto, donde tienen principalmente un papel protector entre el mundo terrenal y el Más Allá. Esa es precisamente su función al pie de las pirámides de Giza. Asumida por las poblaciones cananeas y por extensión fenicias, siguió cumpliendo la misma labor aunque especialmente vinculada con el árbol de la vida y el trono (Uroz 2006: 128). Al igual que para el caso de la serpiente, en el Mediterráneo en general y en la península Ibérica en particular existen numerosos ejemplos donde esta función es claramente visible (Jiménez Ávila 2003: 232 y ss.; Uroz 2006: 129-130; Chapa y Belén 2011: 160).

En cuanto a los leones alados, como bien comenta Jiménez Ávila no son numerosos en la iconografía de los bronces fenicios, aunque sí lo son en la asiria y en la urartea (Jiménez Ávila 2003: 235). Como las esfinges, su papel también es el de proteger y garantizar el tránsito feliz al Más Allá con multitud de ejemplos visibles desde el Antiguo Egipto hasta el mundo ibero (García Cardiel 2009; 2012).

Por último, han sido varios los autores que han llamado la atención sobre lo novedosa que pudo ser la representación de un vaso à chardon alado en la toréutica fenicia (Fernández Gómez 1989: 214; Jiménez Ávila 2003: 236). La alusión a una escena de las características del relato de Gilgamesh y los diversos mitos de Glauco adaptándose a la escatología funeraria fenicia explican el novedoso recurso iconológico. Ya el propio Fernández Gómez se percató de que las alas que presenta la pieza dotan a ésta de un carácter sagrado, más si cabe cuando de su boca sale un posible astro que representaría al propio difunto divinizado (Fernández Gómez 1989: 211).
Sobradamente conocida es la utilización de los vasos à chardon como contenedores funerarios en Tarteso. A propósito de su forma, no ha escapado a la interpretación por parte de algunos investigadores el paralelo entre este tipo de recipientes y el perfil caliciforme inspirado en las flores (López Pardo 2006: 137; Olmos 2007-2008: 112; Escacena y Coto 2010: 161). Y no menos citado y trabajado en publicaciones científicas ha sido el tema del vaso como vehículo en el que recorrer los confines del mundo o conectar el mundo terrenal con el celestial. Famoso es el caso de la tradición griega, en la que el Sol viajaba en un cuenco por la noche impulsado por el Océano. También es célebre el episodio de Heracles navegando en una copa hacia Tarteso (López Pardo 2006: 137-140; Olmos 2007-2008: 112).

El uso de este recipiente no es en absoluto una novedad de las poblaciones del suroeste peninsular. F. López Pardo trató esta cuestión hace una década rescatando la tesis de P. Cintas sobre el origen egipcio de esta forma cerámica, habiéndose encontrado en cementerios egipcios desde el Reino Nuevo. Tampoco es ajena esta forma a necrópolis de tradición fenicia y púnica como las ubicadas en Cartago, Malta, Sicilia y Cerdeña, entre otras. Su carácter sacro queda fuera de toda duda, no ya por su aparición en numerosas necrópolis del Mediterráneo o por la presencia del ejemplar grabado en la fuente de El Gandul, sino por encontrarse igualmente en santuarios de tradición fenicia como los de Carmona o El Carambolo (López Pardo 2006: 138-139). Siguiendo nuevamente a López Pardo, ya en el Imperio Nuevo esta forma cerámica encerraba un concepto de regeneración vital. Idea que puede fácilmente trasladarse a la fuente alcalareña, donde el símbolo astral sería un trasunto del nefesh:

El plato ofrece así una escena con un inicio y un final, donde
la nefesh volando en el vaso que representa el renacimiento
vital se dirige desde el punto de partida hacia donde se en-
cuentra la planta cuyo alimento le procurará la Nueva Vida
ofrecida por una divinidad. El espacio que se abre entre am-
bos extremos, el centro oblongo de la bandeja, parece figurar
el «agua primordial» representada por los peces y la ser-
piente sinuosa que se mueve entre ellos, un océano, río in-
menso que debe ser atravesado hasta alcanzar la otra orilla
para obtener la vida bienaventurada

(López Pardo 2006: 140)

En definitiva, desde el mitema del uso de la flor de la resurrección aquí analizado, todos los elementos que aparecen decorando la bandeja de El Gandul son fácilmente explicables. El universo simbólico de la escena 
supone una adaptación de la estructura del mitema a la tradición cananea a partir de referentes propios de su escatología religiosa. No obstante, todavía se puede ir un paso más allá en la interpretación simbólica y funcional de la pieza a través del perfil que presenta la fuente.

\section{EL MITEMA DEL TORO CELESTE}

El descubrimiento en 1958 del tesoro de El Carambolo no sólo dio origen a la moderna arqueología tartésica, sino que además aquel conjunto digno de Argantonio supuso el origen de la tradición historiográfica sobre la forma que se analiza en este apartado. Al buscar paralelos para la forma de los dos pectorales, E. Kukahn y A. Blanco propusieron una buena muestra de elementos con similar perfil procedentes del Mediterráneo oriental:

Como motivo ornamental se encuentra en vasos micénicos, en los tableros de marfil, para juego, de Megiddo, en las pinturas de los palacios asirios y sirios de Khorsabad, Arslan-Tash, TelBarsib, etc., e incluso en lingotes de cobre de la época premonetal que aspiran a reproducir la piel extendida de un buey

(Kukahn y Blanco 1959: 42)

Con dichas palabras se introducían en la literatura específica española los dos grandes referentes hasta el presente para buscar el origen de la forma de los elementos aquí analizados: la forma de la piel extendida de un bóvido y la de unos peculiares lingotes de cobre aparecidos por todo el Mediterráneo e incluso el Atlántico y Europa Central. En esta búsqueda de paralelos para los 'pectorales', Kukahn y Blanco se decantaron por considerar que la forma de los lingotes estaba en realidad basada en el perfil que presentan las pieles bovinas tras su desuello y perfilado. Sin embargo, pocos años después la influyente figura de J. Maluquer de Motes (1984 [1970]: 117-118) propuso relacionar directamente estas piezas con los propios lingotes, y por extensión con las ricas minas tartésicas:

Los grandes pectorales, en realidad, no sabemos cómo se llevarían. Su forma es ciertamente la de los lingotes o galápagos de metal

(Maluquer de Motes 1984 [1970]: 135) ${ }^{4}$

A estas interpretaciones le sucedió el hallazgo de la fuente de bronce forjado encontrada en la tumba 16 de la necrópolis de La Joya. La forma y el material metálico en que estaba facturada dicha bandeja llevó a sus descubridores a proponer como referente directo una vez más a los propios lingotes (Garrido y Orta 1978: 49). Al igual que Maluquer, estos autores se decantaban por una opción y silenciaban otra, quizás dejados llevar por la similitud visual que ofrecían ambos objetos, los cuales tenían la filiación chipriota con la que los autores de las excavaciones de La Joya vincularon muchos de los objetos aparecidos en el interior de sus tumbas (Garrido y Orta 1978).

Tan sólo con posterioridad, tras los hallazgos de los altares de Cancho Roano (Zalamea de la Serena, Badajoz) y de Caura (Coria del Río, Sevilla) se empezó a valorar la

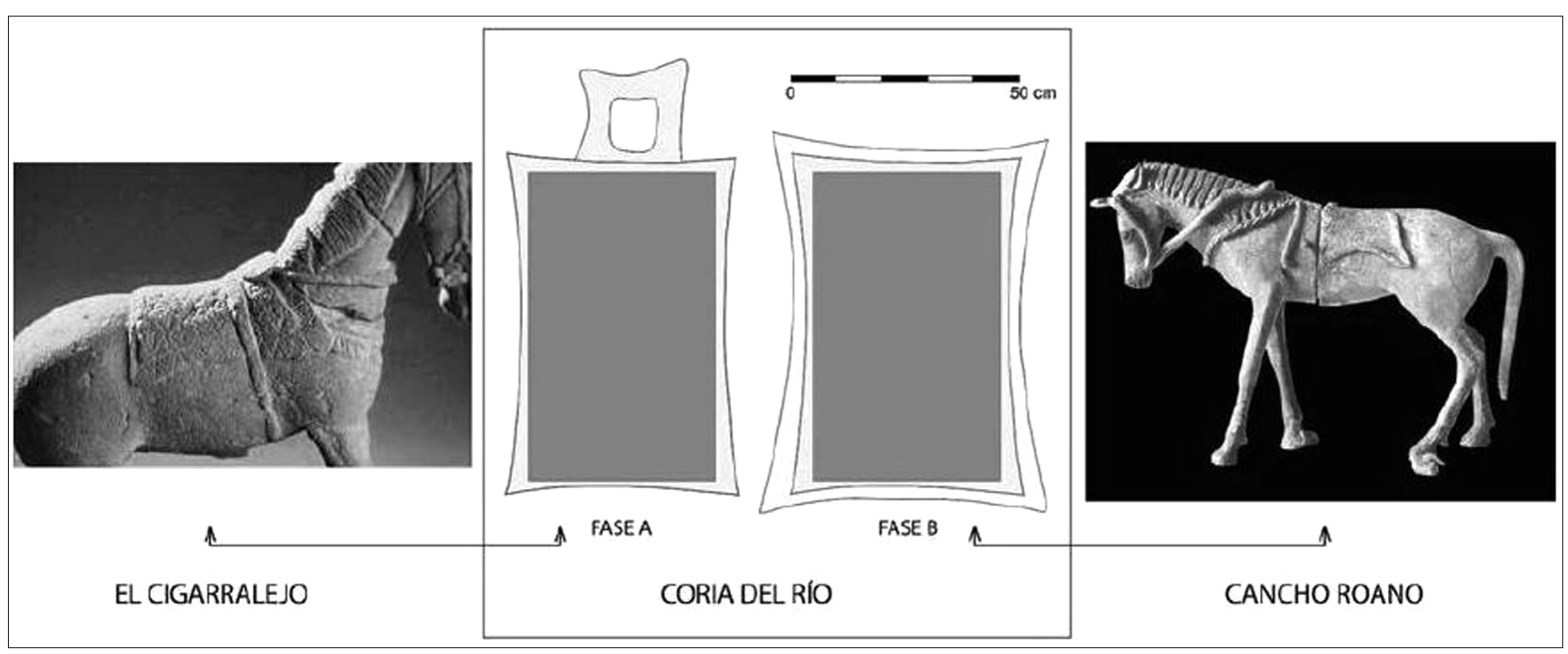

Fig. 4: Altares de las fases A y B de Caura. El primero muestra un receptáculo para libaciones y otros líquidos simulando el cuello que conservaban algunas pieles como se observa en la lengüeta vuelta hacia atrás en la pieza de El Cigarralejo (Mula, Murcia). Por su parte, el ara B es más esquemática y recuerda más en su forma a la montura de la yegua de Cancho Roano (Escacena y Coto 2010: 159). 


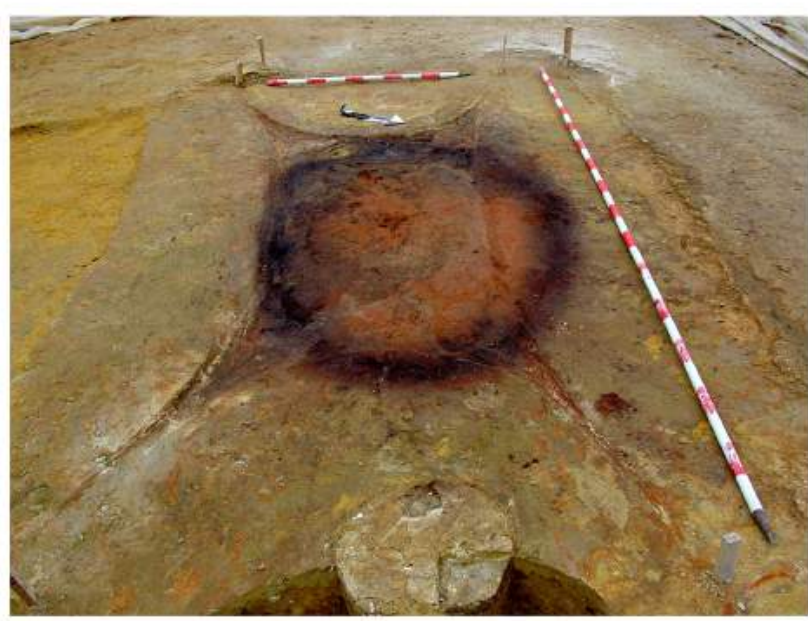

1

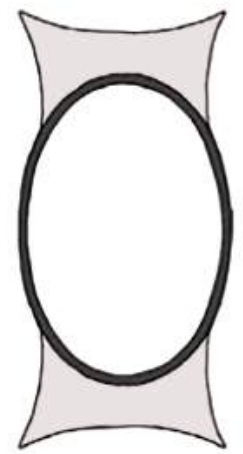

2

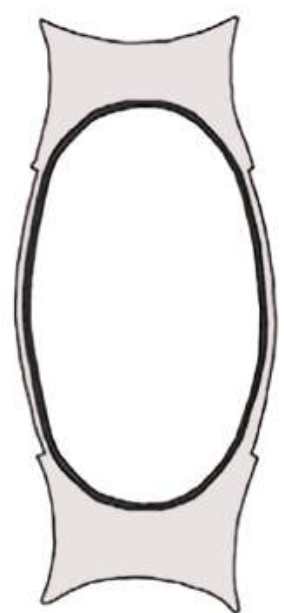

3

Fig. 5: 1) Altar de El Carambolo III. 2) Bandeja de El Gandul. 3) Fuente de La Joya (a partir de Escacena y Coto 2010: 177).

simbología taurodérmica como auténtico leitmotiv de estos objetos. En este sentido hay que destacar la figura de J. L. Escacena, quien como director de las excavaciones del yacimiento de Caura interpretó el ara allí aparecida como el trasunto de una piel de toro tanto por sus características formales, como por las cromáticas y las simbólicas. Para él, el altar del municipio sevillano presenta la característica forma taurodérmica tras su procesado artesanal, mostrando una línea interna paralela a su contorno exterior haciendo alusión al modo en que el pelo de las bestias era recortado. Así se presenta la parte interior de un color rojizo propio del pelaje de animales castaños, mientras la exterior fue decorada con tonos amarillentos dada la coloración que presenta el pellejo depilado del animal. A su vez, la fase más antigua del altar -fase A- tenía un receptáculo para recoger líquidos que estaría imitando al cuello del animal. Apoyando esta idea, las monturas de varias piezas votivas procedentes de El Cigarralejo (Murcia) y de la yegua de bronce igualmente votiva del santuario de Cancho Roano muestran el mismo perfil (Escacena 2000: 177-184) (fig. 4).

Así las cosas, desde finales de los años noventa del pasado siglo, el número de objetos que ha sido relacionado con una u otra forma dentro de la protohistoria peninsular ibérica ha ido creciendo de manera casi exponencial, no sólo en cuantía sino también en importancia dentro de la historiografía. Tanto es así que desde los años noventa se les ha dedicado diversos estudios, en parte o en su totalidad, en los que se sigue como tónica general dar una visión de conjunto de todos y cada uno de los ejemplares con diferentes conclusiones y siempre en clara conexión con piezas orientales (Celestino 1994; 2008; Lagarce y Lagarce 1997; Escacena e Izquierdo 2000; Escacena 2002; 2006; 2007; 2011; Amores y Escacena 2003; Escacena y Coto 2010; Escacena y Amores 2011; Maier 2003; López Pardo 2006; Marín 2006; Vázquez Hoys 2006; Gómez Peña 2010; 2011; 2012-2013; Almagro-Gorbea y Lorrio 2011; Almagro-Gorbea et al. 2011-2012; Tejera y Fernández 2012).

Posicionándome a favor de la propuesta taurodérmica por los motivos expuestos en publicaciones anteriores (Gómez Peña 2010; 2011; 2012-2013), el contorno de la bandeja de El Gandul responde a la característica forma de la piel de un cuadrúpedo extendida. Sus asas reflejan las esquinas apuntadas del pellejo y el óvalo central hace lo propio con la huella cenicienta que se observa en la superficie de numerosos altares taurodérmicos, de modo que el resultado se asemeja muchísimo al del ara de El Carambolo, donde el foco rubefactado excede a la propia superficie del hogar (Escacena y Coto 2010: 177) (fig. 5).

Una primera lectura sobre la simbología de su forma en relación al mitema antes expuesto podría hacer pensar en que la muda de la piel de la serpiente tiene un claro paralelo con la resurrección del difunto en el Más Allá. Sin embargo si esa fuese la explicación, ¿qué sentido tendría representar la piel en la bandeja? ¿Habría que considerar que se trataría de la piel del propio difunto? 
Desde mi punto de vista no tiene mucho sentido apelar a esta interpretación para dar explicación a la forma que presenta la fuente.

Por el contrario, y sin entrar a valorar por falta de espacio las diferentes hipótesis sobre la simbología de este tipo de objetos (Gómez Peña 2012-2013), recientemente he propuesto una nueva interpretación para el simbolismo de la piel de toro extendida (Gómez Peña 2017). Ésta se basa parcialmente en la hipótesis del sacrificio fundacional elaborada por M. Almagro-Gorbea y sus colaboradores (Almagro-Gorbea et al. 2011-2012), si bien la idea propuesta por estos autores necesitaba de mayor recorrido y concreción en algunos aspectos.

El hilo conductor de dicho mitema es el sacrificio del Toro Celeste. En él, el animal es matado por un héroe ahijado del Sol, identificado normalmente con el monarca en una de sus múltiples hazañas heroicas. Tras dicha acción, la piel del bóvido es utilizada como asiento sobre el que se colocan presidiendo un banquete tanto la divinidad solar como el propio héroe. En torno a ella se realiza una comida que reúne a diversos personajes con motivo de un ritual de paso. Éste puede consistir en la fundación de una fortaleza, un templo, un hogar familiar, dar entierro a un difunto o celebrar el Año Nuevo. En función de qué narración se analice se verá que de los aspectos acabados de enumerar faltarán unos u otros, como toda tradición que presenta diversidad y mutaciones con el paso de los siglos. Por el contrario, cuando algunos de estos puntos no son mencionados en los textos, existen otros datos suplementarios que permiten plantear igualmente que se está ante este mitema.

Por motivos de espacio no es posible analizar con la profundidad deseada todos y cada uno de los casos documentados en los que este mitema aparece reflejado (vid. Gómez Peña 2017). Especialmente importante es el sacrificio del Toro Celeste en la Epopeya de Gilgamesh, del que se han visto posibles ecos en la eboraria tartésica a través de una placa de marfil localizada en Medellín (AlmagroGorbea 2002: 66 y ss.). Sin embargo, para ejemplificar lo que con estos casos quiere decirse se recurre aquí a exponer sucintamente varios ejemplos de entre las varias referencias textuales y arqueológicas encontradas dentro del mundo antiguo. En primer lugar la tauroctonía mitraica, a continuación la fundación del palacio de Baal según se recoge en la tradición mitológica ugarítica, en tercer término la fundación de Cartago por parte de Elisa y para finalizar la fundación de la Tebas griega por parte de Cadmo.

\section{MITRA Y LA TAUROCTONÍA}

La visión sobre el mundo mitraico ha llamado la atención de numerosos investigadores desde la obra de F. V. M. Cumont (1903). En este camino historiográfico la interpretación de su iconografía ha sido uno de los pilares sobre los que se han apoyado sus explicaciones. No sólo a la hora de identificar las escenas en sí mismas, sino por supuesto a la hora de interpretarlas tanto en lo figurativo

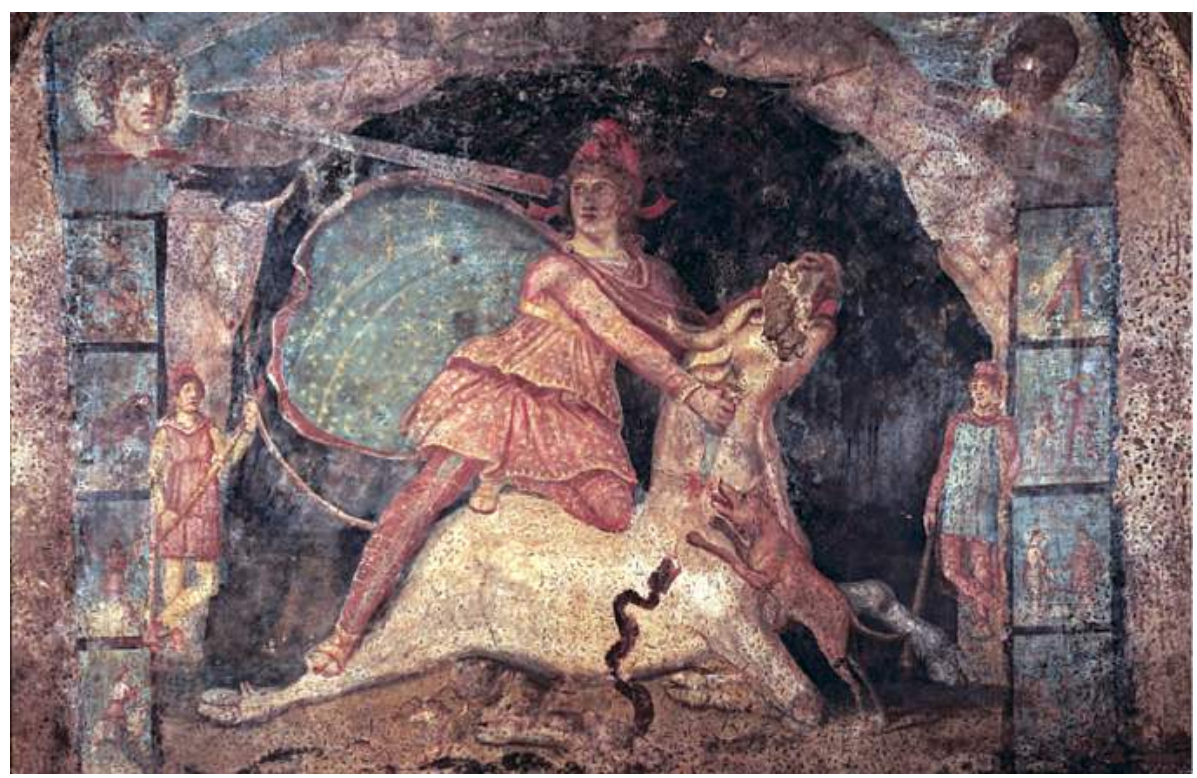

Fig. 6: Escena de tauroctonía procedente del mitreo de Marino (Italia) en la que se representa a Mitra con una capa que simboliza la bóveda celeste mientras el Toro es atacado por varios animales que representarían diversas constelaciones (s. III d.C.) (Juan Sanchis 2016: 115, fig. 96). 
como en lo simbólico, recurriéndose para ello en numerosas ocasiones a paralelos culturales iranios (Cumont 1903) y grecorromanos (Turcan 1986). Mientras, en otro sentido se ha llamado la atención sobre sus referentes astronómicos y astrológicos (Speidel 1980; Sandelin 1988; Ulansey 1989a; 1989b; Beck 2006).

Una de las características más llamativas del culto mitraico es sin lugar a dudas la de los singulares mitreos, espacios de culto situados en un primer momento en cuevas naturales y más adelante en construcciones artificiales que imitaban a aquéllas con una capacidad de aforo limitada a unas decenas de personas. Estos espacios tenían tres zonas diferenciadas. En primer lugar una antecámara. A continuación el spelaeum o spelunca -la cueva-, una sala rectangular con dos largos bancos para realizar banquetes sagrados. Por último, el santuario al fondo de la cueva, donde se localizaban el altar y la imagen de Mitra dando muerte al toro, en la conocida escena de la tauroctonía (fig. 6).

A partir de los escasos testimonios escritos y de las imágenes halladas en los mitreos, se piensa que el dios Mitra nació de una roca -la petra generatrix- bajo un árbol, cerca de un manantial sagrado. Se le suele representar con un gorro frigio, una antorcha y un cuchillo, elementos que portaba desde su nacimiento. Su relación con el toro al que da posteriormente muerte surgió cuando le encontró pastando en las montañas. El joven dios trató de domeñarlo agarrándolo por los cuernos y montándolo sin éxito, si bien consiguió seguir aferrado a su cornamenta hasta agotarlo de cansancio, momento en el cual lo cogió por sus patas traseras y lo cargó sobre los hombros hasta su cueva. A su llegada, un cuervo enviado por el dios Sol le avisó de que debía matarlo en sacrificio, ante lo cual Mitra le clavó el cuchillo en el costado saliendo de su cuerpo trigo y de su sangre vino.

Según la interpretación de R. Beck, los mitreos no habrían sido otra cosa que representaciones del cosmos (Beck 2006: 102-118), donde las figuras de diversos animales y objetos que aparecen rodeando la tauroctonía reflejarían una serie de constelaciones relacionadas con la muerte del Toro Celeste. Así, la bestia no sería otra que la constelación de Tauro, los perros que se arrojan sobre su cuello Canis Major y Canis Minor, la serpiente que repta por debajo del bóvido sería Hydra, el escorpión que trata de agarrarle un testículo Escorpio, el cuervo representaría a Corvus, la pareja de gemelos sería Géminis, y una estrella denominada espiga de trigo que podría ser Espiga, Alpha Virginis de la constelación de Virgo. Incluso en algunas representaciones de la zona germana con extensión hasta el Danubio han aparecido también representadas en la escena una copa por Cráter y un león en referencia a Leo bajo el Toro Celeste (Beck 2006: 31).

Sea cual sea la constelación o fenómeno al que pone rostro Mitra, el principal motivo por el que se trata aquí este asunto es el reflejo de sus ritos. La tauroctonía se acompaña la gran mayoría de las veces de una escena de banquete en la iconografía mitraica. Se trata de una cuestión secundaria a la propia muerte del animal, pero lo realmente importante es que el acto de la comida comunal ocurre sobre la propia piel del Toro Celeste recién defenestrado, apareciendo recostados sobre ella tanto Mitra como el dios Sol. De ello tenemos constancia en varios ejemplos, entre los que se encuentran un fragmento de bajorrelieve encontrado en Konjica (Bosnia y Herzegovina) y actualmente conservado en el Museo Civito Archaeologico di Bologna (fig. 7) y una escena de banquete procedente del Museo Lobdengau (Ladenburg, Alemania) y fechada en torno al 130 d.C. (fig. 8).

\section{BAAL Y LA FUNDACIÓN DE SU PALACIO}

Por lo que respecta al ritual fundacional del palacio de Baal (KTU 1.4, V 44-65 y VI 1-18), en los textos ugaríticos se recoge lo siguiente:

Then Kothar-and-Hasis arrived.

They set an ox before him,

$1.4 v 45$ and a fatling before his face.

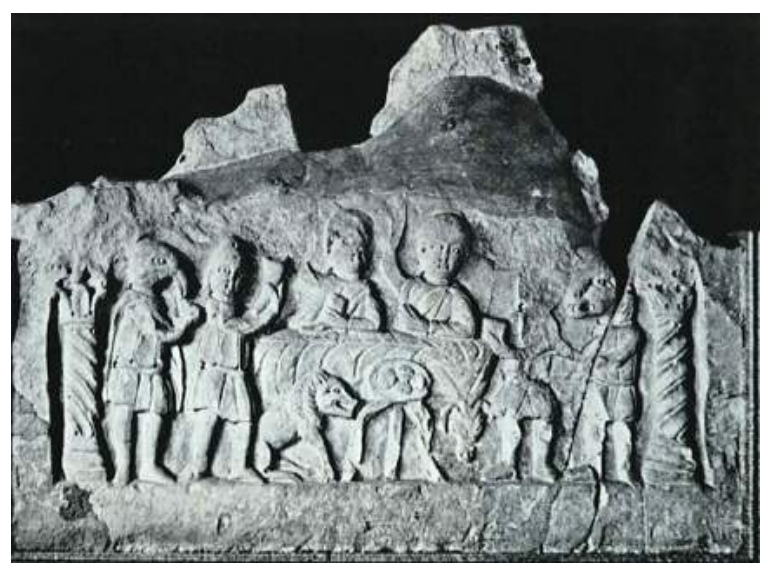

Fig. 7: Bajorrelieve fragmentado del banquete mitraico encontrado en Konjica (Bosnia) y conservado actualmente en el Museo Civito Archeologico Bologna (Juan Sanchis 2016: 410, fig. 548). 


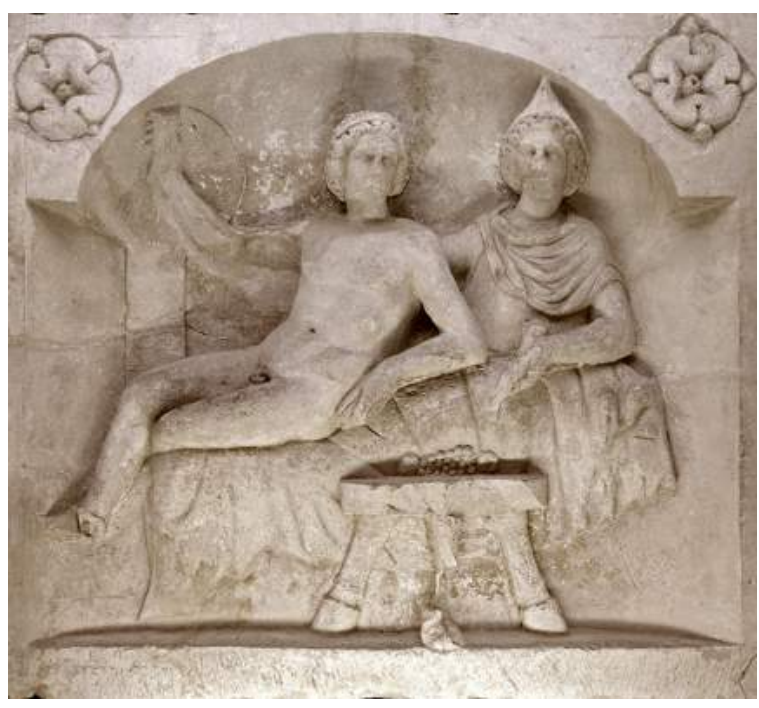

Fig. 8: Bajorrelieve actualmente en el Museo de Lobdengau donde se aprecia a Mitra y el Sol reclinados sobre la piel del Toro Celeste (Juan Sanchis 2016: 330, fig.420).

A seat was prepared and he was seated at the right hand of Valiant Baal, until [the gods] had eaten and drunk. [Then] Val[iant Baal] said,

1.4 v 50 '[De]part, Ko[thar-and-Hasis]! Hasten! [Build] a house indeed; hasten! Construct a pala[ce]! Hasten! [Let] them build a house; Hasten! Let them construct a pala[ce],

$1.4 v 55$ in the midst of the uttermost parts of Saphon. A thousand square yards let the house take up, ten thousand acres the palace!' And Kothar-and-Hasis replied: 'Listen, $O$ Valiant Baal!

1.4 v 60 Understand, O Charioteer of the Clouds! shall I not put a window in the hou[sel, a casement in the midst of the palace?' But Valiant Baal replied:

'You shall on no account put a window in [the house], $1.4 v 65$ [(nor) a case]ment in the midst of the pal[ace]! 1.4 VI I And Ko[thar-and-Ha]sis replied 'You will return, Baal, to [my advice]'. Ko[thar]-and-Hasis repeated his question: 'Listen, I pray, $O$ Valiant Baal!

1.4 VI 5 shall I not put a win[dow] in the house, a casement in the midst of the [pal]ace?' But Valiant Baal replied: 'You shall on no account put a wi[ndo]w in the house, (nor) a casement in the mi[dst of the pa]lace!

1.4 VI 10 Lest [Pidra]y, daughter of Light, should esc[ape] [and Tali]y, daughter of Shower, [should flee?], [or the Be]loved of EI, Yam, [should arise],

[ ] insult and spit (on me).'

1.4 vi 15 And Kothar-[and-HasisJ replied:

'You will return, Baal, to my advice'.

[Quickly] his house they built;

[quickly] they constructed his palace

(Wyatt 1998: 103-105)

Tal y como recoge el texto, Kothar-and-Hasis -divinidad menor cuyo nombre podría traducirse por "Hábil e Inteligente"- sacrifica un bóvido y acto seguido crea un asiento para Baal, colocándose a su diestra. La estrecha relación entre estos dos actos me hace pensar en la posibilidad de que dicho asiento fuese creado con la propia piel del animal, razón por la que se analiza aquí este texto. La escena recuerda al episodio mitraico, pues además de lo acabado de exponer Kothar-and-Hasis se sienta junto a él y comienza un banquete en el que tanto ambos como el resto de dioses comen y beben hasta saciarse. Interesante resulta el momento en el que tiene lugar dicha reunión, pues se realiza justo antes de la construcción del palacio de Baal, que no es otro edificio que su propio templo. A la luz de estos datos, el banquete podría insertarse dentro de un contexto fundacional - o mejor dicho prefundacional-, tónica que podrá verse en posteriores ejemplos dentro del mundo cananeo.

\section{CADMO Y LA FUNDACIÓN DE TEBAS}

La mitología griega narra que Cadmo era hijo de Telefasa y de Agénor, viviendo en Fenicia hasta que Zeus, transformado en toro, raptó a su hermana, motivo por el que tras buscarla sin éxito llegó a Beocia, lugar en el que fundó una fortaleza. Entre las referencias a este episodio se narra el sacrificio de una vaca como ofrenda fundacional de la Tebas griega por parte Cadmo (Almagro-Gorbea et al. 2011-2012: 255-256), por lo que dado el carácter fenicio del personaje parece razonable considerar que el héroe realiza una tradición propia de su lugar de origen y no del de llegada. Así describe Nonno en su Dionysiaca el episodio:

También pasó Cadmo por la región de Ceronea, donde las pezuñas de la vaca se tornaron blancas, de cortar con su paso el polvo resplandeciente. Tras andar las muy sinuosas vueltas de un pétreo camino, se sacudían las blancas manchas de los pies polvorientos. De pronto el pie, profético, de la vaca se inclinó; ella se echó al piso, como anuncio de la ciudad futura. Entonces se cumplió para Cadmo el oráculo Pítico de subterránea voz; colocó la vaca sagrada junto a un altar perfumado, y fue 
a buscar una vertiente de aguas de fuentes para purificar sus manos proféticas, y libar el agua consagrada en la ofrenda sacramental. Pues aún no había surgido, en los cultivos de viñedos, el bonito fruto, maduro, de estación.

[Nono retoma al comienzo del canto $V$ el relato de los actos rituales del sacrificio, interrumpido en el IV 356, cuando introduce la escena del dragón de la fuente Dircea. Con la imagen de la siega Nono describe la aniquilación de los Gigantes nacidos de la tierra por la semilla de los dientes del dragón] Pero tan pronto como Cadmo, a fuerza de cortar los serpentinos trigales de sus batallas, logró segar la espiga de los Gigantes nacidos de los dientes ofreció a Ares como primicias del combate una libación de sangre mezclada con polvo. Luego, lavó sus miembros en la fuente Dirce, que cría dragones; y sacrificó sobre un altar, hecho para honrar a los dioses, una vaca délfica, hermosa ofrenda para Palas. Para dar comienzo al sacrificio, los dos cuernos fueron rociados a ambos lados con molidos granos de cebada. Luego, él extrajo de su tahalí asirio una espada desnuda, que pendía al lado de su muslo; y cortó con ese sable de buena empuñadura los pelos de la punta de la cabeza de largo hocico. Y mientras Teoclímeno cogía a la becerra por los cuernos y tiraba de su cuello para atrás, Tiestes le asestaba un golpe con su hacha de doble filo sobre la vena yugular. Al punto, el pétreo altar de Atenea Oncea se enrojecía con el sangriento chorro de la vaca. Y ante un golpe sobre la frente de la cornuda ternera, la becerra se desplomó a tierra de cabeza. Luego, tras ser desgarrada con el hierro, sus flancos separados con el cuchillo fueron repartidos y simultáneamente se despojó a la vaca del duro cuero que se extendía sobre ella. Después de desplegar sobre el suelo su brillante manto, el mismo señor se encontró fatigado; no obstante, separó la carne cruda de los vigorosos miembros; la cubrió con doble capa de grasa y la fue cortando en pequeñas rebanadas. Luego extendió sobre las brasas las entrañas ensartadas en puntas de hierro y las retiró una vez cocidas durante un buen rato a fuego lento. Inmediatamente, un criado que las trinchaba, atravesadas al medio con un puntiagudo bronce, las llevó en orden y las puso sobre una mesa cubierta de flores al ras del suelo, una vez que hubo levantado los espetones que chirriaban sin interrupción. Un humo perfumado del incienso asirio daba vueltas por el aire, vagabundo. Terminado el sacrificio, llegó el festín; Cadmo cogió y repartió la comida elegida, dando a cada uno porciones semejantes. De este modo la tropa de los convidados depuso su apetito alrededor de una mesa circular hasta que, satisfecha, ya no quiso más

(Non. Dionys. IV, 344-355; V, 1-33; trad. Manterola y Pinkler 1990: 159-160, 167-169)

El sacrificio de la vaca parte de la iniciativa de Cadmo, ayudado en la empresa por Teoclímeno y Tiestes, y tras la muerte de aquélla se reparten sus miembros y se realiza un banquete en el que la carne de la res es consumida previo paso por el fuego. Es interesante reseñar que en este texto ya existe en el lugar del sacrificio un altar hecho de piedra dedicado a Atenea Oncea, por lo que indicar qué función cumple aquí el cuero de la vaca no es fácil de asegurar: ¿hogar, altar, asiento para Cadmo, lugar de la epifanía de alguna divinidad? No obstante, no deja de ser significativo que el hecho ocurra durante la ceremonia previa a la construcción de la ciudad de Tebas, que tuvo en origen el nombre de Cadmea por su fundador, lo que permite relacionar este mito con el esquema del mitema comentado unas páginas antes.

\section{ELISA Y LA FUNDACIÓN DE CARTAGO}

Quizás podría realizarse una interpretación similar de los testimonios que se conocen actualmente sobre la fundación de Cartago por parte de Elisa. Justino narra sobre este episodio que a la muerte del rey tirio Mutón, éste dejó como herederos a sus hijos Pigmalión y Elisa. El primero ascendió al trono, mientras que la segunda acabó casándose con su tío materno Aquerbas -también denominado Siqueo (Virg., Aen. I, 343 y 349)-, sacerdote de Melqart y segundo cargo más importante en Tiro después del propio Pigmalión. Dadas las riquezas escondidas por Aquerbas, el rey decidió matarle para hacerse con ellas, pero Elisa no accedió al chantaje de su hermano y decidió huir junto a gente de su confianza poniendo rumbo a Chipre, donde se une a su séquito el sacerdote de Júpiter con su mujer y sus hijos (Justino, Epit. XVIII, 4. 3-15 y 5. 1-3). Su siguiente destino fue la costa libia, lugar donde según Justino se establecieron como comerciantes, cuya extensión fue conseguida cortando en finas tiras la piel de un bóvido justo después de recuperar fuerzas de un viaje tan agotador (Justino, Epit. XVIII 5. 8-14).

No resulta descabellado proponer a partir de los pasajes citados que el pellejo utilizado hubiera provenido de una res sacrificada en un ritual fundacional del santuario empórico y por extensión de la futura colonia que acabó cumpliendo la función de lugar de comercio, rememorándose con dicho rito el sacrificio primigenio del Toro Celeste tal y como se ha visto en ejemplos previos.

La única diferencia en esta ocasión radica en la necesidad de dar una salida óptima para su gente al desafío planteado por el jefe libio Jarbas, quien en lo que se podría interpretar como un acto de provocación le planteó a Elisa que le cedería tanto territorio para la fundación de su ciudad como extensión pudiera abarcar la piel del bóvido. Ante este problema, la propia Elisa decidió cortar en finas tiras el cuero del animal creando un extenso perímetro y dando así solución al problema isoperimétrico más antiguo conocido. 
Más allá de esta diferencia circunstancial, los elementos que unen este mito con la estructura del mitema son claros. La presencia de una fundadora que no sólo es en este caso reina por ser hija de Mutón sino que también tiene un papel religioso en tanto que viuda del sumo sacerdote Aquerbas, la fundación de un lugar de culto y con él una colonia que recuerda parcialmente al caso de Cadmea, el sacrificio de un bóvido como en anteriores relatos, la recuperación de fuerzas que podría ser una manera de mencionar la realización de un banquete posterior, y por último la construcción de la colonia que de nuevo recuerda en la secuencia de pasos a la erección del santuario de Baal, dios solar, según el mito ugarítico.

\section{LOS 'DIOSES DEL LINGOTE'}

En último lugar se trae aquí el hallazgo de los mal llamados 'dioses del lingote', cuestión abordada en anteriores publicaciones (Gómez Peña 2010; 2011). La primera de ambas figuras representa a un personaje masculino de pie sobre una piel extendida que se localizó en una fosa fundacional de un santuario de Enkomi (Chipre) (fig. 9, A). Su hallazgo en dicha oquedad, excavada en la cella del templo, sacó a la luz no sólo a la estatuilla de pie, sino varios vasos muy probablemente de uso ritual a su alrededor
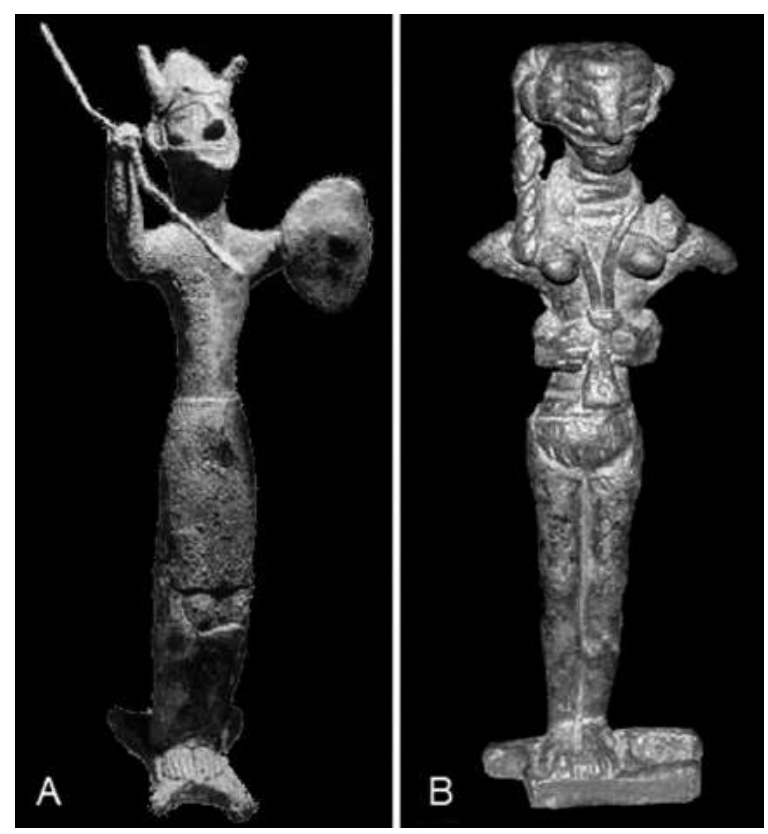

Fig. 9: A) 'Dios del lingote' procedente del santuario chipriota de Enkomi. B) Diosa de la colección Bomford de procedencia incierta (a partir de Celestino 2008: 323-324).
(Schaeffer 1971: 525 y ss.). Por su parte, en el suelo de dicha sala se encontraron restos óseos de diferentes animales entre los que destacan los bucráneos y las cornamentas de toros y de otros bóvidos, así como restos óseos de cérvidos (Schaeffer 1964: 179) que denotan la práctica de sacrificios de animales asociados a los altares presentes en la estancia como los lugares en los que se realizaron.

Relacionada con el 'dios del lingote', existe otra figura, esta vez femenina, procedente de la colección Bomford del Ashmolean Museum de Oxford. Ésta se encuentra también de pie sobre, según la interpretación tradicional, un lingote con forma de piel de bóvido (fig. 9, B). Su procedencia es desconocida pero por sus características formales se le ha otorgado un origen chipriota (Catling 1971).

Las constantes relaciones entre los lingotes de esta forma y la isla de Chipre han sido motivo para asociar ambas estatuillas por parte de algunos investigadores con divinidades de origen chipriota (Catling 1971; Marín 2006: 45), habiendo sido ambas identificadas con una pareja divina relacionada con el trabajo minero-metalúrgico. Sin embargo, dados los precedentes analizados anteriormente, más los recogidos en una investigación previa (Gómez Peña 2017), parece más lógico proponer que ambas figurillas estarían representando a la divinidad apareciendo en un acto de hierofanía sobre la piel del Toro Celeste sacrificado para celebrar un banquete inaugural, lo que daría explicación a la procedencia de la estatuilla masculina en una fosa fundacional bajo el templo chipriota.

\section{LA BANDEJA DE EL GANDUL}

Tras este breve repaso por algunas de las manifestaciones a propósito del uso de la piel de bóvido como asiento para el héroe y la divinidad en un ritual de paso, es posible realizar algunas valoraciones sobre la forma, simbología y función de la fuente. Para ello es necesario partir del supuesto de que las cenizas del difunto estuvieron durante las pompas fúnebres sobre la fuente de El Gandul. De ser cierta esta hipótesis, el monarca podría haber presidido simbólicamente el banquete durante el proceso de heroización. Así, la piel del Toro Celeste habría actuado de base sobre la que reposarían sus restos mientras se daba un baño en la laguna que recoge la almendra central de la pieza. A pesar del peligro que supondría la serpiente, la flor de la resurrección se encontraría a buen recaudo protegida tanto por los leones como por las esfinges. El resultado habría sido la divinización del monarca al completarse su proceso de heroización, visible en el carácter astral del difunto al salir del vaso à chardon . 


\section{BREVES CONCLUSIONES}

Con base en todo lo expuesto anteriormente se concluye que en la bandeja de El Gandul se grabó un universo simbólico de muerte y resurrección. Dicha simbología presenta dos aspectos complementarios que hay que destacar. En primer lugar, los ejemplos representados en la fuente alcalareña reflejan el tránsito de un personaje de alto rango dentro de la protohistoria ibérica al Más Allá gracias a la consecución y custodia de la flor de la vida, la cual le permite comenzar el viaje rejuvenecido y revigorizado. En segundo lugar, la forma taurodérmica de la pieza cobraría sentido desde la tauroctonía acabada de analizar. En los ejemplos anteriormente comentados la piel es utilizada como base sobre la que se colocan la divinidad y el monarca heroizado para dar comienzo a la celebración de un banquete.

Esta simbología claramente oriental encaja bien con las conclusiones técnicas y estilísticas aportadas por los especialistas que se han acercado al estudio de ambas piezas. Tanto J. P. Garrido y E. M. Orta como Fernández Gómez consideran a cada una de las bandejas bien como importaciones orientales (Garrido y Orta 1978: 183) o como producciones fenicias en talleres occidentales (Fernández Gómez 1989: 214). A la última de ambas posibilidades se adscribe Jiménez Ávila, para quien las novedades iconográficas que presenta la bandeja de El Gandul no restan valor a la idea de estar ante creaciones fenicias occidentales, sino que le otorgan un carácter de innovación (Jiménez Ávila 2002: 143), en un proceso que podría englobarse dentro de una occidentalización de las comunidades fenicias (vid. Escacena 2011: 167 y ss.).

\section{NOTAS}

1. Este trabajo se ha realizado en el seno del grupo de Investigación (HUM-949) Tellus: Prehistoria y Arqueología en el sur de Iberia.

2. El uso en estas líneas de términos como el de bandeja o fuente se hace indistintamente con el único afán de dotar al texto de mayor claridad. Se trata así de evitar repeticiones innecesarias que pudieran hacer farragosa la lectura del mismo basándome en palabras asentadas en la tradición historiográfica y que en absoluto están exentas de casar con la función que pudieron tener en origen (Jiménez Ávila 2002: 139).

3. Un breve análisis introductorio sobre el debate entre partidarios y detractores de la influencia mesopotámica en los mitos helenos puede hallarse en E. van Dongen (2008: 233-234).

4. Opinión también defendida por aquellas fechas a propósito de algunos símbolos de las estelas del SO por M. Bendala (1977).

\section{BIBLIOGRAFÍA}

ALMAGRO-GORBEA, M. (2002): Melqart-Herakles matando al Toro Celeste en una placa ebúrnea de Medellín, AEspA $75,59-73$.

DOI: https://doi.org/10.3989/aespa.2002.v75.128

ALMAGRO-GORBEA, M.; LORRIO, A. J. (2011): Teutates. El héroe fundador y el culto heroico al antepasado en Hispania y en la Keltiké, Madrid.

ALMAGRO-GORBEA, M.; LORRIO, A. J.; MEDEROS, A.; TORRES, M. (2011-2012): El mito de Telepinu y el altar primordial en forma de piel de toro, CPAUAM 37-38, 241-262.

AMORES, F.; ESCACENA, J. L. (2003): De toros y de tesoros: simbología y función de las joyas de El Carambolo, Fiestas de toros y sociedad (A. García-Baquero, P. Romero, eds.), Sevilla, 41-68.

BECK, R. (2006): The Religion of the Mithras Cult in the Roman Empire. Mysteries of the Unconquered Sun, Oxford.

BENDALA, M. (1977): Notas sobre las estelas decoradas del suroeste y los orígenes de Tartessos, Habis 8, 177-206.

BOTTÉRO, J. (2015 [1998]): La epopeya de Gilgamesh. El gran hombre que no quería morir, Madrid.

CATLING, H. W. (1971): A Cypriot bronze statuette in the Bomford collection, Alasia I, Tome IV (C. F. A. Schaeffer, dir.), Paris, 15-32.

CELESTINO, S. (1994): Los altares en forma de «lingote chipriota» de los santuarios de Cancho Roano, REIb 1, 291-310.

CELESTINO, S. (2008): Los altares en forma de piel de toro de la Península Ibérica, Las culturas del Próximo Oriente Antiguo y su expansión mediterránea (J. J. Justel, J. P. Vita, J. Á. Zamora, eds.), Zaragoza, 321-348.

CHAPA, T.; BELÉN, M. (2011): Viaje a la eternidad. El grupo escultórico del Parque Infantil de Tráfico (Elche, Alicante), Spal 20, 151-174. DOI: https://doi.org/10.12795/spal.2011.i20.10

CUMONT, F. V. M. (1903): The Mysteries of Mithra, Chicago.

DÍAZ-REGAÑÓN, J. M. (trad.) (1984): Claudio Eliano. Historia de los animales. Libros I-VIII, Madrid.

ELIADE, M. (1999 [1976]): Historia de las creencias y las ideas religiosas. De la Edad de Piedra a los Misterios de Eleusis, vol. I, Barcelona.

ESCACENA, J. L. (2002): Dioses, Toros y Altares. Un templo para Baal en la antigua desembocadura del Guadalquivir, $E x$ Oriente Lux: Las religiones orientales antiguas en la Península Ibérica (E. Ferrer, ed.), Sevilla, 33-76.

ESCACENA, J. L. (2006): Allas el estrellero, o Darwin en las sacristías, Entre dios y los hombres: el sacerdocio en la Antigüedad (J. L. Escacena, E. Ferrer, eds.), Sevilla, 103-156.

ESCACENA, J. L. (2007): El dios que resucita: claves de un mito en su primer viaje a Occidente, Las culturas del Próximo Oriente Antiguo y su expansión mediterránea (J. J. Justel, J. P. Vita, J. Á. Zamora, eds.), Zaragoza, 615-651. 
ESCACENA, J. L. (2011): Variación identitaria entre los orientales de Tartessos. Reflexiones desde el antiesencialismo darwinista, Fenicios en Tartesos: nuevas perspectivas (M. Álvarez, ed.), Oxford, 161-192.

ESCACENA, J. L.; AMORES, F. (2011): Revestidos como dios manda. El tesoro del Carambolo como ajuar de consagración, Spal 20, 107-141. DOI: https://doi.org/10.12795/spal.2011.i20.08

ESCACENA, J. L.; COTO, M. (2010): Altares para la eternidad, Spal 19, 149-185.

DOI: https://doi.org/10.12795/spal.2010.i19.07

ESCACENA, J. L.; IZQUIERDO, R. (2000): Altares para Baal, Arys 3, 11-40.

FERNÁNDEZ GÓMEZ, F. (1989): La fuente orientalizante de El Gandul (Alcalá de Guadaira, Sevilla), AEspA 62, 199-218.

FERNÁNDEZ GÓMEZ, F. (1991): Una fuente de bronce decorada con motivos orientalizantes en el Museo Arqueológico de Sevilla, II Congresso Internazionale di Studi Fenici e Punici, vol. II, Roma, 854-863.

GARCÍA CARDIEL, J. (2009): Renacer entre leones. Una nueva perspectiva de los leones de Pozo Moro (Chinchilla, Albacete), Lucentum XXVIII, 51-68.

DOI: https://doi.org/10.14198/LVCENTVM2009.28.03

GARCÍA CARDIEL, J. (2012): Tránsito, muerte, poder y protección. Leones en el imaginario ibérico, Animales simbólicos en la historia. Desde la Protohistoria hasta el final de la Edad Media (M. R. García Huerta; F. Ruiz Gómez, dirs.), Madrid, 79-90.

GARRIDO, J. P.; ORTA, E. M. (1978): Excavaciones en la necrópolis de La Joya (Huelva) II (3. ${ }^{a}, 4 .^{a}$ y $5 .^{a}$ campañas), Madrid.

GÓMEZ PEÑA, A. (2010): Así en Oriente como en Occidente: el origen oriental de los altares taurodérmicos de la Península Ibérica, Spal 19, 129-148.

DOI: https://doi.org/10.12795/spal.2010.i19.06

GÓMEZ PEÑA, A. (2011): Nuevos datos sobre los altares taurodérmicos asirios y su simbología, Lucentum XXX, 9-24. DOI: https://doi.org/10.14198/LVCENTVM2011.30.01

GÓMEZ PEÑA, A. (2012-2013): Historiografía y metodología taurodérmica: nuevas consideraciones sobre su simbolismo en la protohistoria peninsular ibérica, $A A C$ 23-24, 11-34.

GÓMEZ PEÑA, A. (2017): La piel de toro como símbolo religioso e identitario en la colonización fenicio-púnica de la Península Ibérica desde una perspectiva darwinista, Tesis doctoral inédita, Sevilla.

JIMÉNEZ ÁVILA, J. (2002): La toréutica orientalizante en la Península Ibérica, Madrid.

JIMÉNEZ ÁVILA, J. (2003): Seres híbridos en el repertorio iconográfico de la toréutica orientalizante de la Península Ibérica, Seres híbridos. Apropiación de motivos míticos mediterráneos (I. Izquierdo, H. Le Meaux, eds.), Madrid, 231-260.
JUAN SANCHIS, M. T. (2016): Testimonios y documentos del culto de Mitra en el Imperio Romano, Tesis doctoral, Universidad de Alicante (http: rua.ua.es/dspace/handle/10045/65910).

KUKAHN, E.; BLANCO, A. (1959): El tesoro del Carambolo, AEA XXXII, 38-49.

LAGARCE, J.; LAGARCE, E. (1997): Les lingots «en peau de boeuf», objets de comerce et symboles idéologiques dans le monde méditerranéen, REPPAL X, 73-97.

LÓPEZ PARDO, F. (2006): La torre de las almas: un recorrido por los mitos y creencias del mundo fenicio y orientalizante a través del monumento de Pozo Moro, Madrid.

MAIER, J. (2003): El lingote en rama chipriota o de piel de toro: símbolo divino de la antigua Iberia, Fiestas de toros y sociedad (A. García-Baquero, P. Romero, eds.), Sevilla, 85-106.

MALUQUER DE MOTES, J. (1984 [1970]): Tartessos. La ciudad sin Historia, Barcelona.

MANTEROLA, S. D.; PINKLER, L. M. (trads.) (1995): Nono de Panópolis. Dionisíacas. Cantos I-XII, Madrid.

MARÍN, M. C. (2006): De dioses, pieles y lingotes, Habis 37, 35-54.

MATA, C.; BADAL, E.; BONET, H.; COLLADO, E.; FABADO, F. J.; FUENTES, M.; IZQUIERDO, I.; MORENO, A.; NTINOU, M.; QUIXAL, D.; RIPOLLÈS, P. P.; SORIA, L. (2007): De lo real a lo imaginario. Aproximación a la flora ibérica durante la Edad del Hierro, AAC 18, 93-122.

OLMOS, R. (2003): La imagen en la cultura tartésica, Cerámicas Orientalizantes del Museo de Cabra (J. J. Blánquez, ed.), Cabra, 35-55.

OLMOS, R. (2007-2008): El estanque de la diosa: representaciones de raigambre oriental y mediterránea en la iconografía ibérica, Boletín de la Asociación Española de Amigos de la Arqueología 45, 111-127.

RODRÍGUEZ SOMOLINOS, H. (2006): La planta de la inmortalidad en Grecia y el mito de Glauco de Antedón, EPOS XXII, 11-19.

ROVIRA, S. (1989): Examen de laboratorio de la fuente de El Gandul (Sevilla), AEA 62, 219-225.

SAN MARTÍN, C. (2014): Phoenician metal production in Tartessos, Assyria to Iberia at the Dawn of the Classical Age (J. Aruz, Y. Rakic, S. Graff, eds.), New York, 218.

SANDELIN, K.-G. (1988): Mithras = Auriga, Arctos 22, 133-135.

SCHAEFFER, C. F.-A. (1964): La XVIe Campagne de fouilles de la Mission Archéologique Française à Enkomi-Alasia, en Chypre, Syria LXI, 179-181.

SCHAEFFER, C. F.-A. (1971): Les peuples de la mer et leurs santuaires a Enkomi-Alasia aux XIIe-XIe s. av. n. è., Alasia I, Tome IV (C. F. A. Schaeffer, dir.), Paris, 505-573.

SPEIDEL, M. (1980): Mithras-Orion: Greek Hero and Roman Army God, Leiden.

TEJERA, A.; FERNÁNDEZ, J. (2012): Los dioses de los tartesios, Barcelona.

TORRES, M. (1999): Sociedad y mundo funerario en Tartessos, Madrid. 
TURCAN, R. (1986): Feu et sang: à propos d'un relief mithriaque, CRAI 130 (1), 217-231.

DOI: https://doi.org/10.3406/crai.1986.14367

ULANSEY, D. (1989a): The Mithraic Mysteries, Scientific American 261 (6), 130-135.

DOI: https://doi.org/10.1038/scientificamerican1289-130

ULANSEY, D. (1989b): The Origins of the Mithraic Mysteries: Cosmology and Salvation in the Ancient World, Oxford.

UROZ, H. (2006): El programa iconográfico religioso de la "Tumba del orfebre” de Cabezo Lucero (Guardamar del Segura, Alicante), Murcia.
VAN DONGEN, E. (2008): The study of Near Eastern influences on Greece: towards the point, KASKAL 5, 233-250.

VÁZQUEZ HOYS, A. M. (2006): Una hipótesis sobre la posible relación entre las operadoras cultuales femeninas en la Península Ibérica en época prerromana. Los altares en forma de lingote / piel de toro y las serpientes, RStudFen XXXIV (1), 97-114.

WAGNER, C. G. (2011): El Poema de Gilgamesh: algunas preguntas desde la etnobotánica, la psicofarmacología y la confrontación con los mitos clásicos, ETF(hist) 24, 31-46. DOI: https://doi.org/10.5944/etfii.24.2011.1855

WYATT, N. (2006 [1998]): Religious texts from Ugarit, London. 